\title{
Ias relaciones de Estados Unidos con las potencias medianas en América Latina: los casos de México y Brasil
}

La inserción internacional de América Latina en los setenta estuvo marcada por importantes transformaciones. Los fenómenos de carácter más general permitieron a algunos países del área, al configurar una nueva constelación de variables tanto en el terreno político como en el económico, asumir un nuevo espacio de actuación externa. No se trata de acometer aquí un estudio extenso del por entonces llamado nuevo orden internacional, ni de señalar las principales repercusiones que éste ha tenido en la región latinoamericana. Lo que se desea examinar en este trabajo es la incidencia que este escenario ha provocado sobre las relaciones de Estados Unidos con una categoría de países que en esta etapa pasaron a merecer la denominación de "potencias medianas", "países semi-industrializados", "nuevos países industrializados" o incluso "países emergentes".

Para acotar mejor el alcance de este estudio, debe advertirse que el propósito es focalizar la atención en los dos países de América Latina más marcadamente clasificados en esta categoría: México y Brasil. El conjunto de transformaciones que permitió una nueva proyección internacional de ambas naciones tuvo en común una reestructuración económica y una redefinición política de sus vínculos con los Estados Unidos. En cada caso, empero, los procesos se dieron en forma bastante diferente y muchas veces hasta con resultados opuestos. Es curioso poner de relieve que si bien la simultaneidad de los cambios en la inserción internacional de México y Brasil permitió una aproximación inédita entre ambos países, las diferencias en la naturaleza misma de tales transformaciones constituyen en la actualidad los mayores obstáculos para una articulación bilateral de sus intereses más consistente. Una de las principales razones de este fenómeno reside en el carácter de las relaciones de cada nación con los Estados Unidos y con los condicionamientos externos que dicha vinculación impone.

Desarrollar de partida una comparación entre las relaciones México-Estados Unidos y Brasil-Estados Unidos durante el período reciente podría llevar a una serie de conclusiones bastante simplistas. 
A pesar de que las semejanzas son enormes, existen diferencias estructurales que no cabe desconocer. Es preferible por lo tanto realizar en primer término un análisis de los contenidos específicos de cada dinámica bilateral para luego identificar sus aspectos más comparables.

En lo concerniente al estudio específico de ambas relaciones bilaterales, es necesario formular una aclaración. Se pensó en un principio conceder mayor énfasis, para examinar estas relaciones, a Ia perspectiva norteamericana que a la mexicana o brasileña. Este propósito, sin embargo, no pudo ser satisfecho en igualdad de condiciones, debido a las características particulares de estas dinámicas bilaterales. La trascendencia que para los Estados Unidos tienen sus relaciones con México hizo, necesariamente, la visión norteamericana sobre su vecino del sur más rica y compleja que la elaborada sobre Brasil. El debate político y académico en Estados Unidos se ha profundizado cada vez más en tal sentido, sobre todo a partir del auge petrolero mexicano, generándose de manera inevitable una cantidad de fuentes bastante superior a la que existe para el estudio de las relaciones con Brasil. Puede que este hecho lleve, en algunos pasajes del trabajo, a que determinadas temáticas presenten, en el caso de México, un tratamiento más profundizado.

\section{El DILEMA MEXICANO}

El cuadro de modificaciones en las relaciones Estados Unidos-México durante los últimos diez años se encuentra directamente vinculado a la nueva proyección internacional de este último país. A partir de la segunda mitad de la década de los setenta, se inicia un proceso de redefinición de las relaciones externas mexicanas que alcanza su punto culminante en el período 1979-81. Las exportaciones de petróleo pasaron a constituirse en el eje principal de las transformaciones económicas internacionales del país, posibilitando al mismo tiempo, alcanzar una tasa anual de crecimiento de $8 \%$ (entre 1978-81). La base industrial mexicana, orientada principalmente al mercado interno, fue cediendo un espacio cada vez mayor a la actividad petrolera. En este escenario se superó la crisis que se había iniciado en 1976 y se fortaleció espectacularmente el poder de negociación del Estado mexicano, en el plano doméstico y ex el ámbito internacional'.

Paradojalmente, este proceso significó el agudizamiento de la

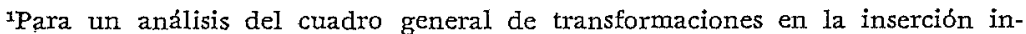
ternacional de México, véase: González, Guadalupe, Incertidumbres de una potencia media regional: Las nuevas dimensiones de Ia Politica Exterior Mexicana, en: Pellicer, Olga (ed.), La Política Exterior de México: Desafios en los Ochenta. cIDE, México, 1983. 
vulnerabilidad externa del país, cuyo comercio exterior se tornó cada vez menos diversificado. Las ventas de productos manufacturados y agropecuarios declinaron en forma drástica, desbaratándose progresivamente el esfuerzo anterior por expandir las exportaciones industriales. Este proceso fue acompañado de una integración económica creciente al mercado norteamericano. En la medida que los Estados Unidos representaron, desde el comienzo, el principal comprador del petróleo mexicano, resultó aniquilado también el intento acometido en los años setenta tendiente a diversificar los mercados externos del país. México había alcanzado relativo éxito en tal empeño, hasta el punto que había conseguido que los Estados Unidos tuviesen una participación de $62 \%$ en sus exportaciones, de las cuales más de la mitad correspondían a ventas de productos manufacturados ${ }^{2}$. De esta forma, el caso mexicano exhibe una dinámica, extremadamente contradictoria y hasta perversa, en la que el nuevo cometido internacional, desde el punto de vista económico o político, involucró una intensificación de la dependencia respecto de los Estados Unidos, agudizándose así todavía más el condicionamiento histórico que implica la existencia de una frontera común de dos mil millas.

Esta realidad originó una nueva agenda de negociaciones entre los dos países, en la que fueron prioritarios los temas relacionados en forma directa con los intereses de ambos. Los temas relativos a la propia soberanía y seguridad nacional se transformaron en el eje central de esta relación. México, que siempre fue una referencia segura en el planteamiento estratégico de Washington pasó, a partir de los años 80, a ocupar un peldaño más alto en la escala de prioridades de la política de seguridad de Estados Unidos.

En la actualidad, México es sin duda el país latinoamericano que mantiene la relación más estrecha con Estados Unidos. La agenda bilateral abarca un conjunto de temas, incluyendo problemas políticos, militares-estratégicos, económicos y sociales. Temas que fueron tradicionales en estas negociaciones están recibiendo ahora una consideración distinta, ante las nuevas realidades que se han configurado para uno $y$ otro país tanto en el plano doméstico como en el internacional. En términos más específicos, la pauta de entendimientos entre el gobierno mexicano y Washington incluye los siguientes ítemes:

1. El desplazamiento de trabajadores mexicanos hacia Ios Estados Unidos, país donde ya existen seis millones de "indocumentados" de esta nacionalidad.

"Toro, Maria Celia, "EI comercio México-Estados Unidos. La realidad desigual y los limites a la colaboración norteamericana". En Pellicer, Olga (ed.) La Politica Exterior de México: Desafios en los Ochenta. CIDE, México, 1983, página 190. 
2. Dificultades asociadas a las relaciones comerciales, destacándose en este sentido la frustración de México ante la legislación proteccionista prevaleciente en Estados Unidos, que afecta a un conjunto de productos mexicanos. Las relaciones comerciales entre lás dos partes lograron un nuevo impulso a partir de fines del decenio de los 70 debido al petróleo, experimentando las transacciones un espectacular incremento de 12,7 a 27 mil millones de dólares.

3. EI flujo de inversiones privadas desde Estados Unidos hacia México, que en 1980 alcanzó un nivel de 5 mil millones de dólares, siendo responsable del $50 \%$ de las exportaciones de manufacturas mexicanas. Muchas son las presiones que ejerce Estados Unidos en favor de una legislación más liberal para los inversionistas extranjeros en México.

4. El endeudamiento externo mexicano, un $40 \%$ del cual ha sido contratado en la banca estadounidense. Desde 1982 este tema ha venido ocupando un lugar de preeminencia en las negociaciones entre los dos países, existiendo una enorme insatisfacción por parte de México con relación a las elevadas tasas internacionales de interés, atribuibles a la politica monetaria de Estados Unidos.

5. La exportación de petróleo y gas natural hacia Estados Unidos. A partir de 1982 México pasó a sustituir a Arabia Saudita como principal abastecedor de crudo del mercado norteamericano, haciéndose cargo del $5 \%$ de su consumo externo (Estados Unidos importa todavía el 44\% del petróleo que necesita).

6. El cuadro de tensiones que impera en Centroamérica y el esfuerzo mexicano por desarrollar una política autónoma para la región. Washington ha procurado no transformar este tema en un foco de debate con México, evitando al máximo conceder su apoyo a las iniciativas político-diplomáticas impulsadas por México.

Lo extenso de la gama de cuestiones sumariamente enunciadas demuestra el grado de complejidad de las relaciones entre estos dos países, sea en su dimensión intergubernamental como en la intersocietal. Por el lado mexicano esta complejidad se expresa en el número mismo de agencias gubernamentales cuyo quehacer se vincula directa o indirectamente con este relacionamiento. Se destacan en tal sentido el Departamento de Estado, de Agricultura, del Tesoro, del Trabajo, de Justicia, y el Representante Comercial de Estados Unidos. Durante el gobierno de Carter se llegó incluso a crear un grupo interburocrático orientado a la formulación conjunta de políticas, designádose para tal efecto a un embajador especial para coordinar desde Washington las relaciones con el gobierno de México:

El papel estratégico que México pasó a desempeñar en este período va suscitando en el gobierno y la sociedad norteamericana

$$
\left[\begin{array}{lll}
2 & 4 & 4
\end{array}\right]
$$


una inquietud creciente ante los riesgos de la inestabilidad politica en el país vecino. Esta inquietud aparece más vinculada a la gravedad de los temas que configuran actualmente la agenda de acuerdos bilaterales, que a la política mexicana en cuanto tal. El desarrollo económico y la recuperación de México de su reciente crisis financiera se transformaron así en inquietudes importantes para el sector privado y el gobierno de Estados Unidos.

En su artículo acerca de la evolución de las relaciones entre los dos países en el último tiempo, Bruce Bagley comenta este hecho poniendo de relieve: "Una economía mexicana sana es esencial para evitar el estallido de la inestabilidad política en México, cuyas secuelas afectarían a Estados Unidos, y para fortalecer el armazón político y económico de una comunidad más amplia de naciones del Caribe y Centroamérica"2. De acuerdo a este mismo autor, un cuadro de inestabilidad política en México podría representar una seria amenaza para los intereses económicos y la seguridad de Estados Unidos. A partir de una visión bastante pragmática, Bagley pondera tanto las inquietudes de carácter nacionalista como la orientación de la política exterior mexicana, sugiriendo que en función de los intereses norteamericanos debiera evitarse recurrir a determinado tipo de presiones. $\mathrm{El}$ autor recomienda que Estados Unidos preste mayor atención a los asuntos que más sensibilidad revisten para los mexicanos, buscando atenuar las tensiones que pudieran perjudicar el avance hacia una "relación mutuamente favorable y de veras interdependiente entre ambos países"3.

\section{La agenda económica}

El hecho que México se haya transformado en el principal exportador de petróleo para el mercado estadoun:dense ha erosionado, inevitablemente, el esfuerzo que venía desplegando su gobierno en favor de la diversificación de su clientela internacional ${ }^{\ddagger}$. El petróleo mexicano se encuentra cada vez más integrado al planeamiento energético de Estados Unidos, transformándose en una fuente vital para sus necesidades básicas. La facilidad de acceso al petróleo mexicano ha permitido incluso que la búsqueda de fuentes alternativas de energía por parte de Washington se haga en forma más tranquila, transformándose de hecho en una tercera opción de su política energética (la primera la constituye la conservación de las fuentes existentes; la segunda, la producción interna).

Otra inmensa ventaja que Estados Únidos atribuye a la compra

'Bagley, Bruce, "Mexico: The Promise of Oil", en: Hayes, Margaret D., Latin America and the U.s. National Interest, Westview, Boulder, 1984, p. 126.

'México está tratando de expandir sus ventas a otros paises, entre los que destacan Canadá, Alemania, Francia, Japón, Israel y España, aparte del mercado norteamericano. 
de petróleo a su vecino tiene relación con los efectos automáticos que estas importaciones ejercen sobre el comercio exterior del país. Ninguna otra nación petrolera gasta una cantidad mayor de recursos provenientes de estas ventas en la compra de productos norteamericanos, que México. Al desarrollar este argumento, Richard Manke sostiene: “... dado que en comparación con cualquier otro miembros de la OPEP perteneciente al hemisferio occidental, México gasta un porcentaje muy superior de cualquier incremento en sus ingresos de divisas en la adquisición de bienes y servicios norteamericanos, una política que estimule el aumento de la participación mexicana en el comercio mundial de petróleo redundará en una expansión neta de la demanda por exportaciones de Estados Unidos"'.

A partir de mediados de 1981 México pasó a concentrar cada vez más sus ventas de petróleo en los mercados de su vecino del norte. En consonancia con Ia política del gobierno de Reagan tendiente a incrementar la reserva estratégica de Estados Unidos, las partes suscribieron un acuerdo que comprometía de manera creciente las exportaciones de petróleo mexicano, fijando al mismo tiempo un tope al precio que habrían de alcanzar estas transacciones. En el seno de la administración republicana no existe consenso, sin embargo, sobre la conveniencia de presionar a México por un aumento exagerado de las operaciones de exploración de sus reservas de crudo, en la medida que las secuelas políticas y económicas de este tipo de exigencia podrían ser imprevisibles.

En un informe elaborado por el Pentágono sobre la geopolítica energética de Ios Estados Unidos para el período 1976-2000, México, Canadá y Venezuela aparecen catalogados como proveedores "naturales" de Ias importaciones petroleras norteamericanas. De los tres, México es considerado como el caso más difícil desde el punto de vista político. Similar inquietud se percibe en un documento preparado por la Rand Corporation, bajo el título "Petróleo mexicano y política de Estados Unidos: Implicancias para los años ochenta", el cual sugiere un conjunto de políticas destinadas a articular ẹn mejor forma la política energética mexicana con los intereses de Estados Unidos. En este mismo documento se recomienda el establecimiento de una relación especial con México, en lugar: de seguirle otorgando el mismo trato que se dispensa a cualquier "potencia intermedia" 6 . Se reconoce al mismo tiempo que un tratamiento no discriminatorio resultaría más satisfactorio para el gobierno mexicano, permitiéndole una actuación internacional más autónoma respecto de la Casa Blanca.

'Manke, Richard, Mexican Oil and Natural Gas: Political, Strategical, and Economic Implications. New York, Preager Publisher, 1979, p. 136.

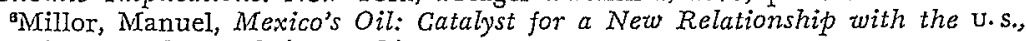
Westview, Boulder, 1984, p. 194. 
El diseño de una relación "especial" a partir de esta nueva realidad tropieza sin embargo con una serie de otras negociaciones que carecen de soluciones de largo plazo. Vale la pena señalar al respecto el problema de la deuda externa y de las relaciones comerciales entre ambos países.

La actitud mexicana en el ámbito financiero se ha caracterizado por una progresiva moderación frente a Estados Unidos y a los organismos crediticios de carácter multilateral. En el cuadro de la reciente crisis financiera latinoamericana, México fue el primer país en vestir la camisa de fuerza que imponen las recetas del Frar. En el segundo semestre de 1984 concluyó una negociación de largo plazo con la comunidad financiera internacional para el pago de su deuda. Uno de los méritos de esta tratativa consistió, desde el punto de vista norteamericano, en la legitimación de la estrategia que la comunidad financiera internacional había adoptado en relación con los países deudores. Esa estrategia obedece a tres objeti vos fundamentales a ser garantizados en el refinanciamiento de los créditos comprometidos: i) el pago de los intereses en una forma relativamente normal; ii) la neutralización de las posturas latinoamericanas más rebeldes; iii) la mantención sin mayores sobresaltos de las reglas de juego del sistema financiero internacional ${ }^{7}$. La denominada "buena conducta" de México resultó un elemento decisivo para este logro. De hecho, las negociaciones con el gobierno mexicano ayudaron en gran medida a conformar un patrón de negociaciones que al principio no parecía estar muy claro para los bancos privados de los países acreedores ni para las agencias financieras multilaterales.

El éxito evidenciado por México en conseguir una capacidad externa adecuada para atender los compromisos más inmediatos de su deuda, al tiempo que satisfacía las exigencias de corregir algunos desequilibrios internos de su economía, facilitó enormemente la segunda vuelta de sus tratativas financieras externas. En septiembre de 1984 el comité asesor de bancos y las autoridades mexicanas dieron a conocer el refinanciamiento de 48.500 millones de dólares de la deuda externa mexicana que vencía entre 1985 y 1990. Conforman ese total: 20 mil millones, que corresponden a los vencimientos durante el mencionado sexenio; 23 mil millones que tienen que ver con el volumen refinanciado en 1982; y 500 millones por nuevos compromisos asumidos en 1983. Se ampliaron, asi, de manera significativa los plazos de las amortizaciones, se garantizó el

TBouzas, Robert, A renegociaçao da divida externa do Mexico, alcances e significado. Brasil: Perspectivas Internacionais, No 3, 1984.

${ }^{8} \mathrm{La}$ primera ronda de tratativas tuvo lugar en diciembre de 1982 , cuando se negoció el refinanciamiento de la deuda externa mexicana con vencimiento previsto entre agosto de 1982 y diciembre de 1984 (alrededor de 23 mil millones de dólares), 
pago de comisiones y se logró llevar adelante las negociaciones y materializar los acuerdos sin la rúbrica del FiMr. En virtud de este acuerdo, México ha quedado liberado de la fatigosa búsqueda de refinanciamientos periódicos durante Ios próximos seis años. Sin embargo, tal vez convenga relativizar estas ventajas. La eliminación de las comisiones, por ejemplo, viene siendo postulada por algunos círculos norteamericanos en función de la propia rentabilidad que representan para la banca privada. La misma argumentación cabe esgrimir en relación con el descenso de los márgenes de intermediación, transformándose en un ahorro marginal en vista de los altos niveles que exhiben en la actualidad las tasas de interés ${ }^{9}$.

En cualquier caso, las negociaciones en el ámbito financiero se encuentran en una fase de tranquilidad y satisfacción recíproca sin precedentes desde fines de 1982. No cabe duda de que el éxito de las tratativas del gobierno mexicano con la comunidad de banqueros internacionales es atribuible en medida importante al propio status que detenta hoy en día México en la escala de prioridades estratégicas de los Estados Unidos. Si este hecho se suma al propio desempeño de la economía mexicana, ya mencionado con anterioridad, y al propósito del sistema financiero de neutralizar una acción conjunta de presión por parte de América Latina, es posible comprender en buena medida los motivos políticos que explican el adecuado encauzamiento de estas negociaciones.

En el ámbito de las relaciones comerciales no ha sido posible todavía alcanzar resultados del mismo carácter. Existe en este caso un conjunto de conflictos pendientes.

Las relaciones México-Estados Unidos experimentan una profunda transformación desde las postrimerías de la década de los 70, generándose una dinámica en virtud de la cual las exportaciones mexicanas de alimentos y bienes manufacturados son sustituidas de. manera gradual por las de crudo. No obstante la progresiva integración económica suscitada por este progreso, se va haciendo difícil desarrollar un campo de negociaciones convergentes:

Por el lado norteamericano, el tratamiento de esta problemática sufrió algunas modificaciones con la transición Carter-Reagan. La disolución del grupo interburocrático para las relaciones entre ambos países, una de cuyas preocupaciones principales consistía en el encauzamiento de la problemática comercial, estuvo acompañada de algunas iniciativas directas por parte de la Casa Blanca. Se destacan en este sentido el encargo de un conjunto de estudios sobre la materia para orientar su discusión en el Congreso. Mediante esta decisión, se trató de sistematizar las posiciones de círculos empresariales, políticos, administrativos y académicos sobre las relaciones

${ }^{9}$ Bouzas, op, cit. 
comerciales con México. Los argumentos de mayor importancia que se manifiestan en estos documentos aluden a la imposibilidad de seguir garantizando un trato preferencial a ese país en caso de que persistiexa en su actitud de no someterse a los acuerdos del GATT. La posición sustentada por la Casa Blanca, sobre la base de tales informes, fue de que se debería tratar de llegar a acuerdos comerciales bilaterales con vistas a lo que entonces se denominó una "liberalización comercial limitada". En este mismo contexto se constituyó una Comisión Conjunta de Comercio que desde el principio concentró sus esfuerzos en el debate y en la posible solución de los conflictos comerciales entre México y Estados Unidos.

Los problemas más graves mencionados por entonces tenían relación con los subsidios a las exportaciones otorgadas por México, y con la utilización del Sistema General de Preferencias, que favorece a algunos productos mexicanos en el mercado norteamericano.

No obstante las presiones de Estados Unidos, México ha mantenido su decisión de no incorporarse al GATT. Entre las principales razones de esta actitud está el hecho de que como exportador de petróleo el país no podría ser objeto de los tratamientos preferenciales que por lo general se conceden a las naciones en desarrollo. $\mathrm{Al}$ mismo tiempo, México ha ido encontrando todo tipo de dificultades para expandir sus exportaciones de manufacturas a Ios Estados Unidos, debido a las barreras proteccionistas existentes en este uiltimo país. Los obstáculos creados por la política arancelaria de Estados Unidos se hicieron sentir con más intensidad a partir de la grave crisis financiera que afectó a México en 1982, cuando el incremento de sus exportaciones se transformó en una meta vital para la recuperación de su economía.

A nivel bilateral los gobiernos de ambos países pasaron a examinar la factibilidad de suscribir un acuerdo comercial que armonizara las diferencias entre las partes. Desde el punto de vista mexicano se trata de garantizar una aplicación menos severa de los impuestos compensatorios, así como de obtener una aplicación amplia del Sistema General de Preferencias. En el caso de Estados Unidos las preocupaciones giran en torno a la política mexicana de subsidios y a las medidas de protección a las inversiones extranjeras, principalmente en el campo de la industria automovilística, petroquímica y computacional. Entre las exigencias que han formulado los norteamericanos se cuenta el desmantelamiento del cEDrs, el más importante sistema de incentivos en favor de las exportaciones mexicanas. De acuerdo con algunas opiniones, el entendimiento bilateral podría demostrarse a la postre aún más perjudicial que la incorporación del país al GATr. En un comentario sobre el tema, Federico Salas señala: "El probable acuerdo con los Estados Unidos incluye un condicionante que lo tornaría más costoso para México 
que un eventual ingreso al GATr, dado que el restablecimiento de las medidas proteccionistas exigiría solicitar la aprobación norteamericana, con el peligro incluso de que el acuerdo quedara nulo si es que no se llega a una transacción satisfactoria" 10 .

Resurge de esta manera el debate acerca de los términos de la llamada relación "especial". Ante los inconvenientes que ha experimentado la economía mexicana y su consiguiente vulnerabilidad vis à vis Estados Unidos, la formalización de un acuerdo comercial puede transformarse de hecho en una camisa de fuerza aún más restrictiva que la aceptación de las normas del GATT. Una alternativa analizada consiste en la adhesión tan sólo al Código de Subsidios y Derechos Compensatorios, de modo de evitarse una participación integral en el conjunto de los acuerdos. En todo caso, el gobierno mexicano reestructuró hace poco su sistema de subsidios a las exportaciones y modificó la participación porcentual mínima exigida al capital nacional en algunos sectores industriales, poniendo de manifiesto una tendencia a someterse a las normas internacionales. El hecho de que se trate de medidas adoptadas por iniciativa del propio Estado permite a su turno proyectar una imagen de relativa soberanía, lo que es muy importante desde el punto de vista interno. Sin embargo, puede que la continuidad de este tipo de maniobras se haga cada vez menos viable, ante lo que cabría denominar, en términos un tanto caricaturescos, la "voracidad" de los Estados Unidos.

En este último país van surgiendo ideas más concretas en el sentido de promover una integración entre las dos economías. El proyecto que manifiesta de manera transparente esta actitud es el relativo a la creación de un Mercado Común que incluya a Estados Unidos, Canadá y México. La idea apareció ya durante el gobierno de Carter, inserta en la estrategia del trilateralismo. A partir de la administración Reagan, su proyección pasa a asociarse progresivamente a la política de seguridad energética de Washington. En síntesis, las medidas que se han sugerido contemplan: i) la liberalización del comercio regional; ii) la liberalización de las políticas sobre inversión extranjera; iii) la reducción de las trabas a los flujos migratorios; iv) la armonización de las políticas de comercio, mi gración y transparencia de capital11.

Cabe señalar que no existe ningún tipo de inquietud con respecto a la homogeneización de las políticas tarifarias, asunto que por lo general constituye el principio básico de la constitución de

${ }^{10 S a l a s, ~ F e d e r i c o, ~ R e l a c i o n e s ~ e c o n o ́ m i c a s ~ M e ́ x i c o-E s t a d o s ~ U n i d o s ~ e n ~ t i e m p o s ~}$ de crisis: Comercio e inversión. Carta de Politica Exterior Mexicana, Año III No 1 , enero/febrero, 1983.

IIPuyana, Alicia, La idea del mercado común de América del Norte y las implicaciones para México, en: Meyer, Lorenzo (ed.), México-Estados Unidos: 1982, El Colegio de México, México, 1982, p. 187. 
un mercado común. No cabe dudas de que México resultaría en extremo perjudicado en este caso, dado que sus productos enfrentarían tanto en el mercado norteamericano como en el mexicano una situación bastante desfavorable. La consecuencia más inmediata consistiría en el aniquilamiento de la industria mexicana, la cual pasaría a dedicarse tan sólo a la fabricación de piezas complementarias para la gran industria norteamericana.

La creciente integración económica de México a Estados Unidos es visualizada por algunos autores norteamericanos como una experiencia comparable a la de California a partir de los años 50. Razonando a partir de la lógica del mercado, Clark Reynolds concluye que México puede obtener resultados económicos similares a los de California en un período incluso más breve. Pese a que señala las enormes diferencias económicas y políticas (en un caso se trata de un Estado dentro de una Federación; en el otro, de un país soberano), no deja de llamar la atención el hecho de que, desde una perspectiva norteamericana, resulte posible establecer un paralelo entre ambas experiencias.

Según Reynolds, la posibilidad de este paralelismo se encuentra asociada a la tendencia misma, inexorable, de interdependencia entre las dos economías. Dicho autor entiende, al mismo tiempo, la reticencia mexicana ante un programa integracionista de tal naturaleza: "Se trata de una nación altiva y poderosa, a la que no le agrada la alternativa de una futura unión con los Estados Unidos. En el mercado existe, empero, un fuerte impulso en favor de una mayor interdependencia. Es posible asimismo que el logro de metas en materia de ingresos, ocupación y crecimiento de ambos países exija un intercambio más pleno que el que desearían los grupos nacionalistas de ambos lados de la frontera"12.

Para este enfoque parecería que existe una disociación ab́soluta entre las dimensiones política y económica, que en un proceso de integración articulan naturalmente, sea a través de la formalización de un mercado común o de la suscripción de acuerdos especificos. En realidad, los más diversos sectores norteamericanos parecen tener dificultades en percibir la dimensión de los intereses nacionales de México envueltos en el conjunto de temas que conforman la agenda de acuerdos entre los dos países. Esta dificultad obedece en parte a la naturaleza de las negociaciones en juego, las cuales generan a menudo una dinámica que sobrepasa los contactos gobierno a gobierno. Cuanto mayor sea la vinculación entre tales negociaciones $y$ los intereses de carácter doméstico en los Estados Uni-

\footnotetext{
12Reynolds, Clark, Las perspectivas económicas y sociales de México y sus implicaciones para las relaciones con los Estados Unidos, en: Reynolds, C. \& Tello, L., Las Relaciones Mexico-Estados Unidos, Fondo de Cultura, México, 1981 , p. 38.
} 
dos, más extenso es el número de actores sociales involucrados. Tal vez el tema que mejor exprese esta articulación entre lo interno y lo externo sea el de las migraciones de trabajadores mexicanos al territorio estadounidense. Teniendo en cuenta los objetivos de este estudio, no se pretende abordar esta cuestión en mayor detalle. El único punto que vale la pena destacar aquí es el de la importancia de esta área de negociación para una planificación de largo plazo de la integración entre las dos economías. Ninguna duda cabe en cuanto a que los intereses que prevalecen en Estados Unidos con respecto a esta cuestión implican un tipo de entendimiento bastante perjudicial para México. La condición de abastecedor de mano de obra barata configura, naturalmente, una situación desfavorable para este país, tanto desde el punto de vista de la incorporación de los trabajadores migrantes a la sociedad norteamericana, como en lo tocante al desarrollo industrial de México.

\section{La brecha politica}

Un último ámbito de negociaciones a ser examinado aquí se refiere a la dimensión propiamente política de las relaciones internacionales de México. Su política exterior se ha caracterizado tradicionalmente por una relativa autonomía vis à vis Estados Unidos. Desde los años 60, cuando el gobierno de López Mateo estableció un esquema propio de relacionamiento con el régimen revolucionario de Cuba, México ha procurado asegurarse un espacio de no alineamiento con Washington en el ámbito interamericano. En el decenio de los 70 tal intento se vio reforzado por el giro tercermundista que imprimió a la política exterior el gobierno de Echeverría, a través de un proceso de diversificación de los contactos internacionales que se tradujo en el establecimiento de relaciones diplomáticas con más de 67 países y la suscripción de 160 pactos y acuerdos internacionales.

La transformación de México en un país petrolero hizo posible un nuevo impulso en dicha dirección, generándose una base material y un poder de negociación hasta entonces desconocido para el país. A pesar de su subordinación a la economía norteamericana, la nueva riqueza del Estado mexicano expandió el horizonte de sus intereses nacionales e internacionales, permitiendo una mayor consistencia a su proyecto de inserción externa. En este marco es posible comprender la activa participación de México en la pugna Norte-Sur, así como sus esfuerzos de aproximación al resto de los países latinoamericanos. Este ámbito de actuación se vio sin embargo en buena medida disminuido a causa de las transformaciones que ha experimentado en el último tiempo el contexto internacional, las cuales llevaron progresivamente a una restricción de los espacios 
que se habian abierto con motivo de lo que se dio en llamar el "nuevo orden internacional".

Junto a este afán por una acción externa más diversificada, el Estado mexicano pasó a abocarse al diseño de una política regional que permitiese una mayor articulación política y económica con America Central y el Caribe.

Desde el punto de vista económico, la intensificación del involucramiento de México con esta área ha sido una meta difícil de logxar. Las transacciones comerciales centroamericanas y caribeñas tienen como contrapartes principales a los paises capitalistas avanzados, entre los que se destaca, como es obvio, Estados Unidos. Dado que se trata básicamente de economías agro-exportadoras, a México se le hace bastante difícil generar con esta región una relación de complementaridad que exhiba características similares a las que existen con el mercado estadounidense. De hecho, lo que tiende a imperar a menudo es una relación competitiva entre Ia economía mexicana y los países de América Central y el Caribe.

En lo tocante a la dimensión política, sin embargo, el desempeño de México en esta zona acusa algunos progresos espectaculares. A pesar de no haber jugado un papel de mayor trascendencia durante el proceso revolucionario nicaragüiense, México se ha transformado en un actor decisivo para la legitimación internacional del gobierno sandinista. Buscando crear rápidamente un ámbito de involucramiento político y económico con Nicaragua, el gobierno mexicano adoptó un conjunto de medidas diplomáticas y de asistencia técnica y financiera, con el objeto de contribuir a consolidar la revolución sandinista. En cuanto a El Salvador, la primera iniciativa de trascendencia fue el reconocimiento, junto con Francia, a mediados de 1981, de las fuerzas guerrilleras como uno de los actores que deberían ser tomados en cuenta en las negociaciones políticas internas de aquel país. Durante el gobierno de López Portillo, por otra parte, los entendimientos con Guba alcanzaron una nueva dinámica, que se manifestó en una serie de visitas presidenciales reciprocas.

La aproximación del gobierno mexicano a las fuerzas izquierdistas de la región centroamericana creó a partir de 1981 un campo de divergencias con los Estados Unidos. El advenimiento de los republicanos a la Gasa Blanca y la política de éstos dirigida a militarizar la región contribuyó en forma decisiva al agravamiento de las discrepancias entre las partes. Tales divergencias pasaron a expresarse a los niveles bilateral y multilateral. En el ámbito interamericano uno de los primeros episodios que dejó de manifiesto este distanciamiento se dio en la Asamblea realizada por la okA en 1981, cuando se procedió a votar la resolución de apoyo a las elecciones en El Salvador. En el seno de Naciones Ưnidas, por otra 
parte, México ha condenado de manera sistemática todo tipo de acción militar del gobierno norteamericano en el área centroamericana.

Es evidente que algunos sectores norteamericanos abrigan la esperanza de que México modifique sustancialmente su actuación en América Gentral, de forma que resulte más favorable a los intereses de Washington. Se trata sin embargo de una expectativa de muy difícil materialización, en términos de la política interna de México, que aparte de percibir que la existencia de una política regional constituye un imperativo para los intereses nacionales del país, entiende la acción mexicana en América Central como una instancia de manifestación de posiciones independientes vis à vis la Casa Blanca. En este marco, una iniciativa como la del Grupo de Contadora se erigió claramente en una propuesta alternativa a la política de desestabilización y de presencia militar norteamericana en la región.

En el ámbito bilateral el gobierno de Reagan viene procurando que la cuestión centroamericana no sobrecargue las tensiones de la relación de Estados Unidos con México. La Casa Blanca ha tratado de evitar que este desencuentro político se transforme en una pugna diplomática de envergadura. Ya durante la visita del presidente norteamericano a México en 1983 resultó evidente la intención de no arribar a ninguna forma de entendimiento, aunque sin que se generara, al mismo tiempo, un ambiente conflictivo ${ }^{13}$.

Este empeño no se ha traducido en compulsiones adicionales por parte de la administración republicana vis à vis las posturas antiintervencionistas asumidas por el actual gobierno mexicano. La indiferencia de Washington ante el quehacer del gxupo Contadora quedó de manifiesto en particular en su tentativa de bloquear, junto con los gobiernos centroamericanos, el apoyo a la solución pacificadora que venía siendo negociada. Por otra parte, no obstante la amplia legitimidad internacional de los esfuerzos diplomáticos desplegados por México, se hace bastante difícil que éstos logren un éxito más concreto ante el tipo de acciones que impulsa la Casa Blanca.

\section{LA IMPPASSE DE LAS RELAGIONES GON BRASIL}

A partir de los años 70, las relaciones económicas externas de Brasil comenzaron a experimentar un proceso de transformación, cuya característica principal consistió en una tendencia a la creciente diversificación. La continuidad de esta tendencia hizo posible que se configuraran, a mediano plazo, las condiciones materiales para

${ }^{13}$ Chabat, Jorge, La entrevista De la Madrid-Reagan: Iogros y desacuerdos. Carta de Polfitica Exterior Mexicana, Año III, N9 4, julio/agosto, 1983. 
un nuevo proyecto politico de inserción internacional de Brasil. En consonancia con un proceso de distensión política en el ámbito doméstico, se puso en aplicación en 1974 una propuesta de polftica externa que apuntaba en lo esencial a la ampliación de los espacios de actuación internacional del país. Se articulaba así, a un desempeño económico ya existente, un programa específico de política externa que pretendía asegurar para Brasil un nuevo papel en el escenario mundial. Vale la pena recordar aquí que esta propuesta fue formulada en un contexto en el que el establecimiento de un "nuevo orden internacional" generaba, como es obvio, un campo de acción menos rígido para los países emergentes del Tercer Mundo14.

El replanteamiento de las relaciones Brasil-Estados Unidos a partir de 1974, con el abandono de la política de alineamiento automático, constituyó el paso inicial y más decisivo de la política exterior acometido por el gobierno de Geise15. Ello estuvo directamente asociado a un nuevo perfil de dependencia del país, caracterizado por una tendencia declinante de la participación de Estados Unidos en las actividades económicas externas del Brasil (comercio exterior, inversión extranjera y endeudamiento externo).

Tras una primera etapa de desinteligencias, durante la administración Carter, el gobierno brasileño logró consolidar un alejamiento político respecto de la Casa Blanca, lo que le significó expandir automáticamente su espacio de desempeño diplomático ${ }^{16}$. Fue en este contexto que sus relaciones con las demás naciones capitalistas avanzadas se intensificaron y diversifjcaron, en tanto que se profundizaron las bases de cooperación con la región latinoamericana $y$ el Tercer Mundo en general.

A partir del gobierno de Reagan las relaciones distantes entre Brasilia y Washington fueron siendo reemplazadas gradualmente por una agenda de tensiones en el campo económico y de divergencias en el terreno político. Las discrepancias entre ambos gobiernos tuvieron desde el principio como eje principal la reacción de Brasil ante los supuestos globales en que se fundaba la polftica exterior de la administración republicana. En el campo polf́tico se suscitó de inmediato un enfoque bastante crítico vis $\grave{a}$ vis el proyecto de recrudecimiento de un orden bipolar y de la consiguiente escalada norteamericana. En el ámbito económico, el motivo principal de

${ }^{1}$ Para formarse una idea general de la inserción internacional de Brasil en la década de los setenta, véase: Wayne A. Selcher, Brazil in the International System: The Rise of a Middle Power, Westview, Boulder, 1981.

${ }^{15}$ Véase Lima, M. R. S. \& Moura, G., A trajetória do pragmatismo: uma análise de política externa brasileira, Dados No 25 (3), 1982.

ropara un examen de Ias relaciones Brasil-Estados Unidos durante el gobierno de Carter, véase: Hirst, M., As Relaçoes Brasil-Estados Unidos no Gontexto da Nova Ordem Intemacional (mimeo) x Reunión Grupo de Relaciones Internacionales cracso, Puerto Rico, 1981. 
desacuerdo habrían de constituirlo los costos para los países en desarrollo de la polftica de recuperación puesta en vigor en Estados Unidos.

En la actualidad, las relaciones Estados Unidos-Brasil se desenvuelven en un terreno de difíciles entendimientos. La profunda crisis financiera que se abatió sobre la economía brasileña a partir de 1982 puso de manifiesto de manera evidente determinadas incompatibilidades entre los dos países. Al mismo tiempo, la creciente vulnerabilidad económica de Brasil redujo en medida apreciable su poder de presión en el ámbito internacional. A ello hay que agregar la propia realidad política del país que enfrentó en el período 1983-84 un proceso de redefiniciones y realineamientos internos. En este contexto, la crisis final del régimen militar debilitó aún más la capacidad de negociación externa del Brasil.

Del lado estadounidense, existen importantes intereses comunes con Brasil, que han de ser defendidos, sobre todo en lo tocante al terreno económico. Sin embargo, dentro de la escala de prioridades de la política exterior del gobiemo de Reagan, dichos intereses no justifican una dedicación mayor a los vínculos con Brasilia. Se percibe así, hasta ahora, un desgaste creciente en las relaciones entre ambos pafses. Vale la pena recapitular la historia reciente de las pugnas bilaterales que ocasionan este deterioro.

\section{Los desencuentros en el ámbito económico}

La política económica aplicada a fines de los años 60 por el gobierno brasileño ponía el acento, desde el punto de vista de las relaciones externas del país, en la captación de recursos en el sistema financiero internacional a través de empréstitos e inversiones, y en la concentración de los esfuerzos en el incremento y la diversificación de las exportaciones. La realización de este proyecto pasó a estar asociada directamente a la configuración de un nuevo perfil de dependencia externa de Brasil, que tenía como rasgo fundamental la atenuación de los vínculos económicos con Estados Unidos. Este proceso se hizo especialmente notorio a partir de 1974, coincidiendo con el aumento del precio internacional del petróleo que se desató por entonces.

En cuanto a las exportaciones, es interesante señalar que la disminución de las transacciones con Estados Unidos resultó compensada principalmente por la intensificación de las relaciones comerciales con América Latina, Africa y Japón. Dentro de esta dinámica, Ilama especialmente la atención el hecho de que en 1980 el porcentaje de exportaciones con destino a América Latina haya llegado a ser casi el mismo que para Estados Unidos. También en lo concerniente a las inversiones extranjeras se suscitaron modificaciones de importancia. El volumen de inversiones aumentó en $1.000 \%$ 
(de 1,7 a 17,5 en miles de millones de dólares) en el përíodo 19691980. En este proceso, los acontecimientos más importantes fueron la entrada y estabilización del capital japonés y el predominio del capital europeo.

Gabe aludir asimismo a las alteraciones que muestra la composición de la deuda externa del Brasil. En 1971, ella correspondía en un $61 \%$ a obligaciones contratadas con instituciones financieras norteamericanas, y el saldo con fuentes europeas. Ya en 1980 la significación relativa de los compromisos con entidades norteamericanas había caido al $40 \%$ del total, en tanto que los contraídos con similares europeos había aumentado al $44 \% \%^{17}$.

El éxito del proyecto de diversificación de las relaciones económicas externas del Brasil se mantuvo hasta los primeros traumas ocasionados por su crisis financiera a partir de 1982. El impacto que la política monetaria del gobierno de Reagan provocó sobre la economía internacional dio origen a una dinámica asimétrica. En efecto, cada paso que Estados Unidos daba hacia su recuperación económica tenía como contrapartida una inmersión cada vez más profunda de algunos países industrializados y del Tercer Mundo en general en estrategias de corte recesivo. La caída de las importaciones de estas economías afectó por consiguiente en forma directa la. estrategia de diversificación que había estado impulsando Brasil. Al mismo tiempo, los sucesivos aumentos de las tasas. internacionales de interés estrangularon por completo las relaciones en el ámbito financiero, pasando ellas a concentrarse tan sólo en la renegociación de los compromisos ya acumulados. Este cuadro adquirió especial gravedad ante el hecho de que el $75 \%$ de la deuda externa del Brasil había sido contratada a tasas de interés fluctuantes.

En este contexto, los temas principales de las negociaciones Estados Unidos-Brasil estuvieron representadas por los efectos de la política monetaria y comercial de la administración Reagan sobre la economía brasileña. A partir de 1982 las negociaciones en el ámbito financiero se fueron deteriorando de manera progresiva. Habiendo suscrito más de media docena de cartas-intenciones con el FMI, Brasil quedó sumido en una situación de absoluta dependencia respecto de las condiciones impuestas por el sistema financiero internacional. En un primer momento la estrategia de las agencias económicas brasileñas consistió en tratar de establecer una negociación de gobierno a gobierno que permitiese una mayor flexibilidad frente a las duras exigencias recesivas del FMr. Tal intento se vio totalmente frustrado, ante el escaso interés de Estados Unidos: en

${ }^{17}$ Goes, Walder. Brazil turns to Western Europe: Changing Perspectives. Trabajo preparado para el Centro de Estudios Brasileños, Escuela de Estudios Internacionales Avanzados, The Johns Hopkins University, Racine, Wisconsin, mayo, 1981. 
asumir mayores responsabilidades en lo concerniente a la deuda del Brasil.

En cuanto a las negociaciones con la comunidad financiera, en las que los bancos norteamericanos han jugado sin duda un papel crucial, los términos de las tratativas han sido muy perjudiciales para Brasil. Al analizar este hecho, Paulo Nogueira Batista Jr. centra su atención en el conjunto de condiciones desfavorables que imperan en estas tratativas. La primera se relaciona con el tipo de intereses cobrado al Brasil, que en casi todos los casos ha correspondido a la Ilamada tasa prime. En segundo lugar, Brasil ha aceptado una indexación trimestral de los intereses, acrecentando así todavía más la subordinación del costo de sus compromisos a los aumentos de dichas tasas. A ellas hay que agregar una serie de recargos, aparte de un elevado margen nominal de intermediación, todo lo cual repercute sobre el volumen total de compromisos asumidos por el país. Según Batista Jr., "si sumáramos todos esos factores, llegaríamos a la conclusión de que Brasil está pagando hoy en día por esos recursos captados en el marco del préstamo jumbo de 6.500 millones de dólares, el equivalente al $15-16 \%$ al año, esto es casi cuatro veces más que la inflación norteamericana en 12 meses, en circunstancias que esos bancos han estado pagando el $11,5 \%$. Queda de manifiesto por tanto que el margen efectivo de intermediación es del orden de los 4 puntos porcentuales. No sólo la tasa básica ha subido a causa de la combinación política monetaria de Estados Unidos/otros factores, sino que también es muy alto el costo adicional que Brasil debe pagar para obtener crédito externo... "18.

En el campo comercial, los entendimientos Brasil-Estados Unidos van configurando un marco cada vez menos favorable desde el punto de vista brasileño. A partir de la situación internacional recesiva, los términos de intercambio con los Estados Unidos comenzaron a expandirse de manera sistemática, pasando de $17,6 \%$ en 1981 al $20 \%$ en 1982 y al $23,1 \%$ en 1983 , tomando como referencia el volumen total de exportaciones del país ${ }^{19}$. Esta tendencia, empero, no ha alterado en absoluto la inflexibilidad del gobierno norteamericano en reláción a su política arancelaria. De hecho, el recrudecimiento del proteccionismo en Estados Unidos viene afectando cada vez más a las exportaciones brasileñas. Entre 1976 y 1982 el porcentaje de las ventas del Brasil al mercado norteamericano que se encuentran sometidas a gravámenes proteccionistas aumentó del 40 al $65 \%{ }^{20}$. Las negociaciones en torno al acero representaron uno

\footnotetext{
${ }^{18}$ Batista Jr., Paulo Nogueira, Evoltı̧ão Recente das Relaçoes Financeiras entre o Brasil $e$ os Estados Unidos, presentación realizada en el encuentro "As Relaçoes Estados Unidos-América Latina: na perspectiva brasileira", IRI/PUC-RJ., agosto, 1984.

${ }^{10}$ Relatório do Banco Central, Rio de Janeiro, febrero, 1984.

${ }^{\infty}$ Gazeta Mercantil, Săo Paulo, abril de 1984.
} 
de Ios fracasos más representativos en este campo de disputas. Los Estados Unidos, como el mayor comprador de acero brasileño (27\% de las exportaciones se dirigen al mercado estadounidense), tornó bastante desfavorable para Brasil las negociaciones de un acuerdo para establecer cuotas, de carácter similar al que fue negociado con la Comunidad Económica Europea.

Al mismo tiempo que Estados Unidos ha ido estableciendo mayores trabas al ingreso de productos brasileños a sus mercados, se han intensificado las presiones ante el gobierno de Brasilia para que éste aplique una política de mayor estímulo en favor de las importaciones norteamericanas. Un mecanismo claramente utilizado con tal propósito ha sido el de los préstamos del Eximbank a este país. De un total de 1.500 millones de dólares otorgados en 1983, Brasil se vio obligado a destinar 1.200 millones a la adquisición de bienes procedentes de Estados Unidos. A ello se agregan las reinvindicaciones norteamericanas para que el gobierno brasileño aplique una política más liberal en relación a algunos sectores de inversión, entre los que destaca el problema especifico del área de la informática.

La necesidad de una mayor apertura de mercados de países como el Brasil fue abiertamente defendida en un artículo reciente escrito por William Brock, del us Trade Representative. EI mensaje del embajador Brock parece bastante claro cuando afirma: "La liberalización del comercio no puede darse en un solo sentido; tiene que ser recíproca. Es necesario que los países industrializados liberalicen sus mercados $\mathrm{y}$ racionalicen sus sectores menos competitivos. Sin embargo, nuestra capacidad de actuar en esta forma se verá reducida de manera considerable si las naciones en desarrollo no participan en un esfuerzo de buena fe para llevar adelante las reformas adecuadas. Especialmente en el caso de los países en desarroIlo más avanzados, carece de fundamento que ellos insistan en mantener barreras al comercio que son inconsistentes con el nivel de desarrollo económico que han alcanzado o con el grado de competitividad de sus exportaciones. Para que todos los países se favorezcan con una nueva ronda, cada uno debe estar dispuesto a hacer concesiones"'21.

El afán norteamexicano de garantizar una extensa libertad de mexcados no se aplica sólo al comercio internacional de bienes primarios y secundarios. Washington ejerce asimismo una presión creciente en el ámbito del GAIr para que sea incluida también el área del comercio de servicios. A partir de la victoria norteamericana en la reunión de 1982, y que significó que esta problemática se transformara en un área de estudios del GATT, se va configuran-

nBrock, William, Trade and Debt: The Vital Linkage, Foreign Affairs, Vol. 62, NQ 5, p. 1091. 
do en la práctica un nuevo campo de divergencias Brasil-Estados Unidos. El incremento de las exportaciones brasileñas de servicios va abriendo frentes importantes para las vinculaciones externas del pais, en especial con el Tercer Mundo. Someter este proceso a una reglamentación internacional significaría, sin duda, afectar la capacidad de Brasil de mantenerse en este mercado en las mismas condiciones de competitividad que en la hora presente.

Los temas que conforman la pauta de negociaciones económicas hacen avizorar un futuro difícil. Las necesidades de la economía brasileña para superar su crisis y retomar un patrón de crecimiento dentro de los mismos moldes que venían siendo sustentados en los años 70 son por entero incompatibles con los intereses norteamericanos. La presencia de ambos pafses en el mercado internacional se ha ido tornando cada vez más competitiva, perdiendo de manera progresiva su carácter complementario. La participación brasileña en el sistema mundial de intercambios como exportador de manufacturas y de servicios (además de las ventas al exterior bastante diversificadas de productos agrícolas) hace cada vez más difícil el restablecimiento de una relación de complementariedad con la economía norteamericana.

No cabe dudas que en Estados Unidos existe una visión bastante realista sobre la potencialidad económica del Brasil. Asimismo, para algunos es bastante claro que los cambios protagonizados por Brasil en sus relaciones económicas externas plantean por sí solos la necesidad de un patrón positivo de entendimiento entre ambas partes. La pregunta que surge es cómo alcanzar ese patrón sin caer en un voluntarismo irreal. Al examinar el nuevo papel internacional que está jugando Brasil, Margaret Hayes, por ejemplo, afirma: "Los intereses de Estados Unidos en Brasil y el cambiante papel de ese pais en la comunidad internacional corresponden a los de un aliado tradicional, un socio económico importante con un volumen significativo de intercambio comercial, inversiones cuantiosas e institucionales, un compromiso común con los sistemas políticos occidentales, y relaciones militares de extensa data, tanto bilaterales como a través del sistema interamericano. A medida que la influencia norteamericana declina y se fortalecen las economías japonesa y europeas, y en tanto persiste la competencia Este-Oeste por la dominación del emergente Tercer Mundo, los Estados Unidos están vitalmente interesados en reforzar sus vínculos con las potencias dominantes en el mundo en desarrollo"22.

El principal obstáculo para que se produzca lo que la mencionada autora llama "un buen relacionamiento" consiste en la dificultad misma de construir un campo convergente de intereses entre ambos países. Por otra parte, es evidente el hecho de que los Es-

${ }^{2}$ Hayes, op. cit., p. 173. 
tados Unidos disponen de recursos bastante más eficaces para la defensa de sus intereses. Se percibe entonces que el cuadro de discrepancias anteriormente examinado se sitúa en un escenario de profundas simetrías en cuanto al poder de negociación de las partes involucradas. Es en este sentido que, al examinar dicha desigualdad, el embajador Roberto Abdenur, comenta: "... no me parece que estén dadas las condiciones para que Estados Unidos levante súbitamente las barreras proteccionistas que han impuesto al acero brasileño, o al azúcar, a los zapatos, a los textiles y otros productos, por más que nosotros estemos dispuestos a abrir a los Estados Unidos nuestra polftica de informática, nuestra política nuclear, etc. ..."23.

En este contexto adquiere extrema importancia la dimensión política de las relaciones Estados Unidos-Brasil, tanto en lo concerniente a las cuestiones económicas, como a las de naturaleza política propiamente dicha. En la medida que la solución concreta de las cuestiones anteriormente mencionadas no parece configurar un desafío fácil para ninguno de los dos, la conducción política de sus negociaciones se convierte en un tema crucial. Este proceso no puede, sin embargo, disociarse de los proyectos más globảles de política internacional de los dos países.

\section{El alejamiento politico}

Las relaciones políticas entre Brasilia y Washington vienen experimentando un proceso de desgaste y deterioro desde mediados de la década de los 70. A partir del advenimiento de la administración Carter se desataron una serie de tensiones entre los dos gobiernos, atribuibles fundamentalmente a la reacción brasileña ante las nuevas políticas que el gobierno demócrata se propuso aplicar en América Latina. Ellas abarcaban la política de derechos humanos, la no proliferación nuclear y el desarme, las tres banderas polítícas más significativas de la plataforma electoral de Garter. Las presiones norteamericanas sobre el gobierno brasileño para llevar adelante estas políticas demostraron ser totalmente ineficaces, provocando a la postre un enfriamiento de las relaciones políticas entre los dos países.

La política exterior brasileña formulada desde el principio por el gobierno de Geisel tenía como fundamento la idea de la ruptura del alineamiento politico automático a Estados Unidos. Para alcanzar dicho objetivo se adoptó la estrategia de desarrollar una política exterior de estilo pragmático, con el objetivo de generar las

"Abdenur, Roberto, presentación realizada en el encuentro "As Relaçoes Estados Unidos-América Latina: A perspectiva brasileira", IRI/PUC-RJ, agosto, 1984. 
condiciones internas y externas para que Brasil dejara de pertenecer al área de influencia de Estados Unidos. No cabe dudas de que las fricciones Carter-Geisel terminaron reforzando aún más esta opción.

En términos conceptuales se buscaba conferir un sentido más amplio a la inserción de Brasil en el mundo occidental, cambiando una relación de carácter exclusivo con los Estados Unidos, por una red diversificada de contactos y entendimientos con las naciones industrializadas ${ }^{24}$. Sobre la base de este enfoque el gobierno brasileño pasó a impulsar una política exterior que procuraba sustituir el espacio de la discordia bilateral por el de la ofensiva multilateral. Se pretendía al mismo tiempo configurar un nuevo ámbito de relaciones con el Tercer Mundo, mediante la elaboración de un conjunto de políticas específicas para el Africa negra, el Medio Oriente y la América Latina. El desarrollo de una vinculación SurSur más expedita y consistente, aparte de constituir un objetivo en sí mismo, apuntaba a fortalecer la posición de no alineamiento en relación a Estados Unidos.

El distanciamiento político entre Brasilia y Washington llevó a que surgiesen en Estados Unidos, en el período final de la administración Garter, algunas reflexiones en torno a las relaciones con Brasil. En este marco en diciembre de 1980 se divulgó un informe elaborado por la Comisión sobre las relaciones Estados Unidos-Brasil, de la Universidad Johns. Hopkins, por una iniciativa conjunta de académicos y empresarios, brasileños y norteamericanos ${ }^{25}$. El documento admitía la existencia de un distanciamiento entre los dos países, sugiriendo que esta situación fuese corregida de inmediato. Se postulaba entonces echar nuevas bases para las relaciones, que asignasen a Brasil un nuevo status internacional. El reconocimiento de Brasil en cuanto a "potencia emergente" debería impedir que dicho distanciamiento repercutiese en forma negativa sobre Estados Unidos. Se afirmaba entonces: "La Comisión acredita que la emergencia exitosa e independiente de Brasil en el concierto internacional no es hostil a nuestros intereses y puede desempeñar un papel constructivo en la comunidad mundial"26. La propuesta básica de la Comisión era que las relaciones Brasil-Estados Unidos fuesen abordadas en una dimensión bilateral, debiendo evitarse nuevas desinteligencias que afectasen la dinámica de las transacciones privadas entre los dos países.

Otros sectores divulgaban, por esta misma época, un mensaje de

\footnotetext{
"Véase: Sardenberg, Ronaldo, "A polftica externa brasileira nas últimas duas décadas" (mimeo), Ministério das Relaçoes Exteriores, 1980. Véase también Lafer, Celso, O Brasil e a Crise Mundial, Perspectiva, São Paulo, 1984.

${ }_{25 R}$ Report of the Comission on United States-Brazilian Relations, Johns Hopkins University, diciembre, 1980.

sordem.
} 
cuño más conservador en lo tocante a las relaciones Brasil-Estados Unidos. Esta perspectiva se fundaba en la idea de que las políticas del gobierno de Carter en América Latina, y en el Brasil específicamente, habían arruinado la antigua pauta de relación. Se acusaba por consiguiente a la administración demócrata de haberse enajenado un amigo tradicional de Estados Unidos, creando un distanciamiento que sólo perjudicaba los intereses norteamericanos ${ }^{27}$. Se hacía imprescindible pues restablecer dicha amistad. De algún modo ésta era la visión subyacente en los primeros intentos del gobierno de Reagan por acercarse nuevamente a Brasilia.

La visita de Thomas Enders a Brasil, en su carácter de Subsecretario Adjunto para Asuntos Latinoamericanos, constituyó en agosto de 1981 el primer paso en dicha dirección. La pretendida revitalización de los vínculos entre los dos países demostró casi de inmediato ser poco favorable desde el punto de vista de la política exterior brasileña. El deseo de involucrar a Brasil en los esfuerzos de la administración Reagan por reeditar la guerra fría, a través de acuerdos de seguridad en el Atlántico Sur, constitufa un fuerte indicio en tal sentido. Aparte de configurar un retroceso en cuanto a una posición no alineada junto a Estados Unidos, cualquier tratativa en esta dirección amenazaba con aniquilar la política de acercamiento de Brasil al África negra. La visita del Subsecretario y la actuación misma del Embajador norteamericano en Brasilia evidenciaban asimismo el propósito de vincular el reacercamiento Brasil-Estados Unidos a un aislamiento de la Cancillería brasileña. Para algunos sectores del gobierno norteamericano el Itamaraty era el principal responsable de la resistencia de Brasil a involucrarse en acuerdos plenos con Estados Unidos.

El fracaso de tales intentos llevó a que poco a poco fuese surgiendo, en la realidad, un campo más extenso de divergencias que de entendimientos entre los dos países. Fue configurándose un número creciente de posiciones políticas discordates, en función del propio desempeño internacional del gobierno de Reagan.

Temas cruciales para la política exterior brasileña pasaron a ser sistemáticamente ignorados o menospreciados por Washington. Un ejemplo notable se dio con respecto al diálogo Norte-Sur, cuyo desarrollo se vio totalmente bloqueado por Washington, en alianza con otras naciones capitalitas avanzadas. Otro caso, de naturaleza más específica, lo constituyó la negativa de Washington a suscribir el nuevo Tratado Internacional del Mar, después de una serie de maniobras para dilatar al máximo su votación en el seno de la onv. También en el ámbito interamericano las diferencias pasaron a ser bastante explícitas, tanto en relación a América Central como en

${ }^{2 T E s t a ~ i d e a ~ e s t a ́ ~ c o n t e n i d a ~ c l a r a m e n t e ~ e n ~ e l ~ a r t i c u l o ~ d e ~ F o n t a i n e, ~ R o g e r, ~ " T h e ~}$ end of a beautiful Relationship, Foreign Policy, N9 28, 1977. 
la posición asumida por Estados Unidos durante la guerra de las Malvinas.

La visita del presidente Reagan a Brasil en diciembre de 198? significó la primera división de aguas en esta escalada. Pese a una agenda de negociaciones bastante difícil, la visita se dio en un clima de comunicaciones relativamente positivo. Entre los hechos que ayudaron a aliviar las tensiones estaba el de las negociaciones recientemente llevadas a cabo en el seno del GATr. En virtud de tales acuerdos, el gobierno brasileño consiguió postergar por más de dos años la utilización del crédito premio en favor de sus exportaciones. Como contrapartida, Estados Unidos obtuvo el apoyo brasileño para impugnar la política de concesión de subsidios, otorgados por la Comunidad Económica Europea, a los productos agrícolas, y para promover la realización de estudios sobre el comercio de servicios.

El principal resultado de la visita de Reagan consistió en el establecimiento de cinco grupos de trabajo, por un período estipulado de seis meses, con vistas a crear instancias formales de negociación en las siguientes áreas: i) problemas financieros y comerciales; ii) asuntos nucleares; iii) cooperación científica y tecnológica; iv) cooperación en el campo del aprovechamiento pacífico del espacio exterior; v) cooperación en el campo de la industria militar.

La conclusión de los trabajos de los cinco grupos tuvo lugar formalmente durante la visita del Secretario de Estado norteamericano a Brasil en febrero de 1984. En realidad, la creación de estos grupos modificó muy poco el bajo perfil de las relaciones Brasil-Estados Unidos. Se mantuvieron prácticamente en el mismo nivel las diferencias en las distintas áreas, en las que ya se habían manifestado previamente las dificultades de negociar. Puede mencionarse a modo de ejemplo los textos finales del Acuerdo sobre Cooperación en Ciencia y Tecnología y el Memorándum de Entendimiento sobre Cooperación Industrial-Militar28. En ambos casos predominaron expresiones bastante vagas, con ausencia de programas concretos y de compromisos significativos entre las partes contratantes.

La importancia política de la suscripción del memorándum de entendimiento sobre la industria militar no puede, sin embargo, ser descartada por completo. Fue el primer documento de esta naturaleza que el gobierno de Reagan firmó en América Latina y puede originar un nuevo campo de presiones por parte de Washington. Las especulaciones relativas a la suscripción de un nuevo acuerdo militar entre los dos países llevó a las autoridades militares brasileñas a exponer, durante la visita de Reagan a Brasil, la necesidad

${ }^{2}$ Memorando de Entendimento entre o Governo da Repriblica Federativa do Brasil $e$ o governo dos Estados Unidos da América Referente a Cooperação em Experimentos Aeroespaciais empregando foguetes de Sondagem. Ministerio de Relaciones Exteriores, Secretaría de Informaciones del Gabinete. 
de que se diferenciaran al máximo los entendimientos en marcha sobre cooperación industrial-militar, de los términos del acụerdo de 1952 denunciado por el gobierno de Geisel en 1977. El acuerdo militar de 1952 contenía una asistencia de carácter mucho más amplio sobre entrenamiento y suministro de materiales bélicos, que los entendimientos iniciados en 1982.

El tema más controvertido al respecto pasó a constituirlo la posibilidad de vincular la exportación de tecnología norteamericana a un poder de restricción de los mercados de exportación de materiales bélicos brasileños. La suscripción de este memorándum abrió, por una parte, la posibilidad para Brasil de adquirir equipo bélico con tecnología norteamericana. Pero, por otra parte, puede significar que Washington exija a Brasil licencias especiales para la exportación de este material. Teniendo en cuenta que países como Irak, Irán y Libia figuran entre los principales clientes de armamento brasileño, no es difícil prever importantes presiones por parte de las autoridades norteamericanas respecto del control de este intercambio. En la propia industria bélica brasileña se libra en la actualidad un debate respecto de la necesidad de importación de componentes y de transferencia de tecnología occidental. El resultado de esta discusión podría reflejarse por cierto en el contenido del segundo memorándum, el cual deberá ser negociado con Estados Unidos, con vistas a regular el traspaso de tecnología.

En lo concerniente a la cuestión nuclear, el gobierno norteamericano pretendía alcanzar dos objetivos fundamentales a través de la formación de un grupo específico sobre el tema: el reinicio de la colaboración con el Brasil y la disposición del gobierno brasileño de adherir al Tratado de No Proliferación Nuclear (TNT). El término del trabajo de este grupo no significó empero mayores avances en relación a estos puntos. En cuanto al área de ciencia y tecnología, una de las principales reivindicaciones de Estados Unidos ha sido la apertura del mercado brasileño a sus microcomputadores. La legislación brasileña, muy restrictiva con respecto a la adquisición de equipos extranjeros, sería aquí el principal punto de mira del gobierno norteamericano. Este tema constituye un punto extremadamente sensible en Brasil, en función de los propios avances del país en el ámbito de la computación, motivados, incluso, por el fuerte apoyo de los cuadros técnico-militares, explicitados de manera categórica en la formulación de una política nacional de informática. La posición norteamericana, a su turno, cuenta con el respaldo de algunos sectores empresariales brasileños aliados a fuertes intereses privados de Estados Unidos ${ }^{29}$.

A despecho de la pluralidad de la agenda de negociaciones Brasil-Estados Unidos, brevemente examinada en este trabajo, no ca-

${ }^{20} \mathrm{O}$ Globo, Rio de Janeiro, 6 de abril de 1983. 
ben dudas de que las cuestiones decisivas pertenecen al ámbito de las relaciones económicas. Los entendimientos con el Fondo Monetario Internacional, con el Departamento del Tesoro, e incluso con el sistema financiero norteamericano dependen cada vez más de sus tratamientos políticos. Por otro lado, el hecho de que la administración Reagan siga en el poder hasta 1988 implica la mantención de márgenes bastante estrechos de negociación, que sólo podrían expandirse en virtud de una decisión política del propio gobierno brasileño. Sin embargo, la creciente dependencia respecto de Estados Unidos, tanto desde el punto de vista financiero cuanto comercial (ya mencionada antes) hacen aún más espinoso este ámbito de acción. La evolución de este escenario dependerá en medida importante de la propia dinámica política que se registre en Brasil. La posibilidad de que se desencadena de hecho un proceso de transición democrática tal vez se traduzca en el reconocimiento al pás de una mayor credibilidad en sus negociaciones con el exterior.

\section{ALGUNOS PUNTOS DE CONIPARAGión}

Después de este breve análisis de las relaciones México-Estados Unidos y Brasil-Estados Unidos, pueden apreciarse las diferencias que existen entre ambas dinámicas bilaterales. Estos rasgos disímiles obedecen no sólo a la evolución reciente de estas vinculaciones, sino, también, a las raíces históricas de cada una. Tanto en el caso de México como en el de Brasil existe un pasado de relaciones con Estados Unidos que gravita significativamente sobre la trayectoria contemporánea de éstas.

Los dos países desempeñaban papeles de la mayor trascendencia en la esfera interamericana durante el diseño del proyecto hegemónico de Estados Unidos en la región. Al mismo tiempo, los espacios que uno y otro ocupaban eran bastante distintos en lo concerniente a los intereses norteamericanos. La propia distancia geográfica creaba en forma automática una diferenciación en lo referente a las posiciones estratégicas y a la importancia económica de los dos países. En tal sentido, estas relaciones bilaterales fueron construidas en forma bastante autónoma, no existiendo mayores interferencias entre los intereses y los campos de acción de los gobiernos mexicano y brasileño. En el caso de Brasil es interesante dejar constancia de que jamás México ocupó en términos políticos un espacio competitivo vis à vis Estados Unidos, como sucedió con Argentina. Por otro lado, en ningún momento posturas de mayor autonomía asumidas por el gobierno mexicano frente a algunos temas de la agenda política interamericana indujeron efectos coaccionantes para Brasil. Pueden mencionarse en tal sentido, algunos ejemplos históricos recientes, como la postura de ambos gobiernos ante la participación norteamericana en el derrocamiento del gobierno 
Mónica Hirst / Las relaciones de Estados Unidos con las potencias medianas...

de Jacobo Arbenz en 1954 en Guatemala, las presiones de la Casa Blanca en América Latina para la ruptura de relaciones con Cuba en el inicio de los años sesenta, y la invasión norteamericana a la República Dominicana en 1965. En estos tres episodios Brasil mantuvo una postura de afincamiento con el gobierno norteamericano, en tanto que México asumió un comportamiento político autónomo.

Una breve revisión ayuda también a entender el universo temático que caracteriza en la actualidad las propias problemáticas que estos dos relacionamientos bilaterales ilustran.

En el caso de México, los condicionamientos de carácter estructural que afectan sus relaciones con Estados Unidos son mucho más evidentes que en el de Brasil. El proceso de integración económica entre los dos países resultó particularmente acelerado durante los últimos diez años, pero sus bases vienen siendo construidas desde mucho antes. La intensidad de esta integración, a su turno, proporcionó siempre una dimensión intergubernamental e intersocietal al relacionamiento entre ambos páses. Con Brasil no se dio nunca este nivel de interacción, siendo bastante precaria la dimensión intersocietal de sus relaciones con Estados Unidos.

Esta diferencia, aunque agudizada todavía más en el último tiempo, lleva a que en nuestros días se libre un debate acerca de cuestiones de naturaleza más estructural en cuanto a las relaciones México-Estados Unidos. Existen en tal sentido algunas diferencias en cuanto a la caracterización de los vínculos entre los dos países, considerando algunos que se trata de una relación de interdependencia $y$, otros, que es una, simplemente, de dependencia.

En el trabajo de Ronfeldt y Sereseres acerca de la naturaleza de la vinculación México-Estados Unidos, realizado en 1977, se aprecia una utilización bastante simplista de la noción de dependencia. En efecto, afirman Ios autores: "La dependencia no es por completo un mito. Pero en términos políticos es limitada y negociable. Pocas son las formas, si es que existe alguna, en que Estados Unidos puede ocasionarle daño a Mexico sin perjudicarse a sí mismo. México podría aprender a coexistir con el sistema norteamericano, como lo hacen algunos de sus superclientes. Por cierto, a Estados Unidos le conviene que México mejore sus capacidades de maniobra y negociación vis à vis el propio Estados Unidos" 30 .

No se trata de acometer aquí una discusión a fondo acerca del concepto de dependencia, sino tan sólo de recordar algunas de sus premisas fundamentales. La primera, que la condición de dependencia se encuentra vinculada a un esquema de vinculación econó-

${ }^{30}$ Ronfeldt \& Sereseres. "The management of U.s.-Mexico Interdependence. Driff Toward Failure", in Grieco, Vásquez \& Garcla (ed.), Mexican-U.s. Relations, Conflict and convergence, University of California, 1983. 
mica estructural, que determina la capacidad de negociación polftia, y no a la inversa como parece sugerirlo la cita anterior. En segundo término, esta situación no se verifica en función de una mayor o menor capacidad de ser perjudicado por otro país, sino por Ia asimetría de capacidad de cada uno para asegurar la defensa de sus propios intereses. Por último, resulta bastante discutible que exista interés por parte de Washington en mejorar el desempeño del gobierno mexicano en sus negociaciones bilaterales, y mucho menos que se superen los vínculos de dependencia que prevalecen en las relaciones entre los dos países.

En este cuadro, el debate en torno a la existencia de una relación interdependiente se hace bastante controvertido. Los autores mencionados postulan que esta interdependencia es real en la medida que una acción de Washington contra México perjudicaría sus propios intereses.

Sin embargo, parece existir una percepción equivocada acerca del significado del concepto de interdependencia. Este tipo de vinculación supone a priori una igualdad de condiciones para negociar, que pueda traducirse en una ecuación equilibrada de costos y beneficios para los países involucrados.

La aplicabilidad de la noción de interdependencia en la caracterización de las relaciones México-Estados Unidos ha sido discutida por algunos autores mexicanos. Carlos Rico, por ejemplo, llama la atención acerca del sentido político de su utilización. Este autor pone de relieve el hecho de que la noción de interdependencia termine disimulando los vínculos estructurales de la dependencia. En tanto que el petróleo pueda alterar estos vínculos, Rico examina esta posibilidad con respecto a la real ampliación del poder de negociación de México a partir de su nuevo papel estratégigico frente a Estados Unidos ${ }^{31}$.

Este debate reviste menos importancia en el contexto del Brasil, existiendo mayor interés por la caracterización política de las relaciones con Estados Unidos. En el caso de México, la dimensión política de esta vinculación exhibe un perfil bastante estable, en función de valores ya consolidados desde el proceso revolucionario que tuvo Iugar en las primeras décadas de este siglo. La institucionalización de este proceso transformó el nacionalismo en un ingrediente permanente de la política exterior de México, al margen de la subordinación económica del país respecto de Estados Unidos. La política exterior del Brasil en el período contemporáneo siempre asignó, a su turno, importancia crucial al tema de las relaciones políticas con Estados Unidos. El debate principal en este caso gira en torno al problema del alineamiento automático en la esfera di-

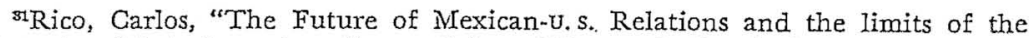
Rhetoric of Interdependence", en: Grieco, Vásquez \& García (ed.), op. cit. 
plomática y militar. A partir de los años 40 , la política exterior brasileña inició la aplicación de un criterio tendiente a negociar el mencionado alineamiento a cambio de una mayor participación de Estados Unidos en el proyecto de desarrollo económico del país. Durante un prolongado período, los distanciamientos entre el gobierno brasileño y Washington fueron atribuibles al fracaso de esta negociación. Es en este sentido que adquiere trascendencia la diversificación de los vínculos económicos externos de Brasil a partir de la década de los 70 , permitiendo un distanciamiento político sobre bases económicas más sólidas entre los dos países.

Más allá de las diferentes variables internas que determinan la naturaleza de las relaciones México-Estados Unidos y Brasil-Estados Unidos, no cabe desconocer la gravitación de los intereses norteamericanos en la definición del perfil de estos vínculos. Es probable que en esta materia los márgenes de maniobra sean más estrechos en el caso mexicano que en el brasileño. De todas formas, existen todavía una serie de posibilidades de acción susceptibles de ser exploradas por los dos países. En consecuencia, se hace imprescindible conseguir una mayor integración tanto en el terreno político como en el económico dentro del propio ámbito latinoamericano. Sin una acción regional coordinada, sobre todo entre los países emergentes del área, será difícil alcanzar avances sustanciales a nivel bilateral o multilateral en las negociaciones con Washington. Los obstáculos que existen en la actualidad para llevar a la práctica un proyecto de esta naturaleza tal vez constituyan el mayor triunfo de Estados Unidos en sus relaciones con las Ilamadas "potencias medianas" de América Latina. 